\title{
Blue-Collar Group
}

National Cancer Institute

\section{Source}

National Cancer Institute. Blue-Collar Group. NCI Thesaurus. Code C19290.

Refers to workers doing skilled or semi-skilled manual labor. A traditionally underserved population. 